\title{
BREAst screening Tailored for HEr (BREATHE) - A Study Protocol On Personalised Risk-based Breast Cancer Screening Programme
}

Jenny Liu 1, 2, ^, Peh Joo Ho 2, 3, 4, ^, Tricia Hui Ling Tan 3, Yen Shing Yeoh 3, Ying Jia Chew 1, 5, Nur Khaliesah Mohamed Riza 2, Alexis Jiaying Khng 4, Su-Ann Goh 2, Yi Wang 2, Han Boon Oh 1, Chi Hui Chin 6, Sing Cheer Kwek 7, Zhi Peng Zhang 8, Desmond Luan Seng Ong 6, Swee Tian Quek 9, Chuan Chien Tan 10, Hwee Lin Wee 2, Jingmei Li 3, 4, , †, Philip Tsau Choong Iau 1, 5, $†$ and Mikael Hartman 2, 3, 5, $\dagger$

$\wedge^{\wedge}$ These authors contributed equally to this work; $\uparrow$ These authors contributed equally to this work

${ }^{1}$ Department of General Surgery, Ng Teng Fong General Hospital, 1 Jurong East St 21, Singapore 609606

${ }^{2}$ Saw Swee Hock School of Public Health, National University of Singapore and National University Health System, Singapore 117549

${ }^{3}$ Department of Surgery, Yong Loo Lin School of Medicine, National University of Singapore and National University Health System, Singapore 119228

${ }^{4}$ Laboratory of Women's Health and Genetics, Genome Institute of Singapore, 60 Biopolis

St \#02-01, Singapore 138672

${ }^{5}$ Department of Surgery, National University Hospital and National University Health System, Singapore 119228

${ }^{6}$ Jurong Polyclinic, National University Polyclinics and National University Health System, Singapore 609788 
${ }^{7}$ Bukit Batok Polyclinic, National University Polyclinics and National University Health System, Singapore 659164

${ }^{8}$ Choa Chu Kang Polyclinic, National University Polyclinics and National University Health System, Singapore 688846

${ }^{9}$ Department of Diagnostic Imaging, National University Hospital and National University Health System, Singapore 119074

${ }^{10}$ SOG- CC Tan Breast, Thyroid \& General Surgery, Gleneagles Medical Centre, Singapore 258499

* Correspondence to:

Dr Jingmei Li, Genome Institute of Singapore, 60 Biopolis Street, Genome, \#02-01, Singapore 138672, Singapore. Tel: (65) 6808 8312; Email: lijm1@gis.a-star.edu.sg

\section{Abstract}

Background: Routine mammography screening is currently the standard tool for finding cancers at an early stage, when treatment is most successful. Current breast screening programmes are one-size-fits-all which all women above a certain age threshold are encouraged to participate. However, breast cancer risk varies by individual. The BREAst screening Tailored for HEr (BREATHE) study aims to assess acceptability of a comprehensive risk-based personalised breast screening in Singapore.

Methods/Design: Advancing beyond the current age-based screening paradigm, BREATHE integrates both genetic and non-genetic breast cancer risk prediction tools to personalise screening recommendations. BREATHE is a cohort study targeting to recruit $\sim 3,500$ 
women. The first recruitment visit will include questionnaires and a buccal cheek swab. After receiving a tailored breast cancer risk report, participants will attend an in-person risk review, followed by a final session assessing the acceptability of our risk stratification programme. Risk prediction is based on: a) Gail model (non-genetic), b) mammographic density and recall, c) BOADICEA predictions (breast cancer predisposition genes), and d) breast cancer polygenic risk score.

Discussion: For national implementation of personalised risk-based breast screening, exploration of the acceptability within the target populace is critical, in addition to validated predication tools. To our knowledge, this is the first study to implement a comprehensive risk-based mammography screening programme in Asia. The BREATHE study will provide essential data for policy implementation which will transform the health system to deliver a better health and healthcare outcomes.

Trial registration: Not applicable.

Keywords: Breast Cancer, Polygenic Risk Score, Mammography Screening, Personalised Medicine, Risk Stratification, Risk Profile, Asian population

\section{Background}

Population-based mammography endeavours to reduce mortality via early detection and prompt treatment (1-3). Despite growing evidence of high heterogeneity of breast cancer risk within populations, breast cancer screening programmes commonly recommend starting mammography screening at age 40 or 50 (4). Furthermore, mammographic screening itself has many limitations - over-diagnosis and overtreatment being prime 
among them (5). While substantially increasing the number of cases of early-stage breast cancer detected, it only marginally reduces the rate at which women present with advanced cancer, as illustrated in the Cochrane reviews (6), Canadian National Breast Screening Study (7) and other studies $(8,9)$. This has generated international interest in a more risk-stratified approach to the current "one-size-fits all” population screening programmes (10-15).

BreastScreen Singapore (BSS), a nation-wide mammography screening programme in Singapore established in 2002 by the Health Promotion Board, invites women aged 50 to 69 to participate in the early detection of breast cancer. However, only $66 \%$ of the target group have reported to ever had a mammogram, and half of them do not adhere to the recommended biennial screening guideline $(<30 \%$ of the target group were reported to attend mammogram every 2 years) (16). Lukewarm responses to these initiatives have been attributed to a low perception of risk and misperceptions of risk factors and knowledge of breast cancer by women (16-21). A number of studies have since proposed that risk-based screening may improve timeliness of screening. Furthermore, under the current age-based screening paradigm, approximately $30 \%$ of diagnosed breast cancer cases in Singapore are women of a younger age than the recommended screening age by the national guidelines (22). The striking difference of $\sim 10$ years in the peak age for breast cancer in between Asian ( 40 to 50 years) and Western ( 60 to 70 years) prompts the need to reconsider screening approaches adapted from Western studies in Asia (23). The design and adoption of risk-stratified approach to screening is needful for timely identification and treatment of these high-risk individuals. 
Personalised screening enhances an age-based screening paradigm by tailoring screening recommendations to the individual's risk profile (24). This reduces the rate of false positive results and over-diagnosis in lower risk individuals, thereby providing a more effective method to identify high risk individuals for intervention (25). Currently, to identify high risk individuals, most screening programmes rely primarily on the evaluation of age, family history, clinical and lifestyle factors, and the testing of pathogenic variants in breast cancer predisposition genes $(14,26)$.

Breast cancer is a multifactorial disease with both genetic and non-genetic risk factors. The Gail model (also known as the Breast Cancer Risk Assessment Tool) was first developed in 1989 for prediction using non-genetic risk factors in Whites, and has since been calibrated and validated for other ethnicities (27). Furthermore, information from the first screen (i.e. mammographic density and false positive status) are indicators of elevated risk (28). The validated Breast and Ovarian Analysis of Disease Incidence and Carrier Estimation Algorithm (BOADICEA) model is able to predict carriership of mutations in known breast cancer genes such as BRCA1 and BRCA2 $(2,29-32)$.

Known pathogenic variants are rare. Due to cost issues, they are usually tested in only high risk individuals $(33,34)$. Common variants (i.e. single nucleotide polymorphism (SNP)) associated with breast cancer risk have been discovered through genome-wide association studies (35). Individually, these SNPs have minimal effect on risk. However, Mavaddat et al. built a polygenic Risk Scores (PRS) - a tally of 313 SNPs - that emerged as a robust means 
to estimate an individual's risk of breast cancer $(36,37)$. The PRS (313 SNPs) is able to reliably predict breast cancer risk, with those in the top centile having a lifetime absolute risk of $32.6 \%$ (38). This PRS has been validated in women of Asian descent (38). Despite a growing body of evidence illustrating the utility of PRS in population screening programmes, policy implementation has been low (3). While the Gail model (27), mammographic density (39) and breast cancer predisposition genes (40) have been incorporated into prior risk stratification studies, implementation of PRS is less common (3).

BREATHE is a landmark study aiming to contextualise a personalised, risk-based screening approach to the Asian population (specific aims are listed in Table 1). The present study endeavours to explore the acceptability and potential impact on changes in screening behaviour of the BREATHE risk-stratified screening programme as the first step towards policy implementation. With the cost-effectiveness of similar approaches validated (41), it is hoped that BREATHE will greatly enhance resource allocation and patient outcomes in the era of precision medicine.

Table 1. Specific aims of BREAst screening Tailored for HEr (BREATHE). The primary aims of our study are to:

1) Study the acceptability of risk stratification to aid women for decision making to attend regular screening

2) Assess if risk-based screening will improve willingness to screen and recall rates

3) Evaluate the cost-effectiveness of changing screening frequencies based on the 
risk-based BREATHE breast screening strategy over the current age-based paradigm.

The secondary aims of our study are:

1) Assess the current level of breast cancer awareness, given the increasing breast cancer education in the recent decade

2) Study the association between breast cancer perceptions (e.g. family history, age, having children) and compliance to regular breast cancer screening

3) Study changes in breast cancer risk factors (e.g. number of children, menopausal status/age)

\section{Methods/ Design}

\section{Study Design}

BREATHE is a prospective multi-centre cohort to study a new modality of breast cancer screening in healthy Singaporean women aged between 35 and 59. We plan to recruit 3,500 participants from two hospitals (Ng Teng Fong General Hospital and National University Hospital) and two polyclinics (Bukit Batok Polyclinic and Choa Chu Kang Polyclinic) over a period of two years. To achieve coverage of all age groups of interest, recruitment targets were allocated as such: $20 \%$ aged 35 to 39 years; $40 \%$ aged 40 to 49 years; and $40 \%$ aged 50 to 59 years. The proportion selected was based on the background population in the 2019 population report published on Singapore Department of Statistics. Participants will be on active follow-up for two years. In brief, enrolled participants will be asked (1) to provide a buccal swap for genotyping at study entry and (2) to answer various questionnaires and surveys at study entry and at the two follow-ups (at $\sim 3$ months and $\sim 2$ 
years after study entry) (Figure 1). All surveys are translated to the three major languages used in Singapore: Mandarin, Malay and Tamil.

\section{Identification of eligible participants}

The study team will identify potential participants (1) through the response to our advertisements on BREATHE (posters, flyers [see Supplementary file 1], and blog.nus.edu.sg/BREATHE) or (2) by approaching them at the participating institutions. The locations include diagnostic departments, women's clinics and waiting areas of the participating institutions. Responders to our advertisements can either call our hotline, email or fill up an online registration form (see Supplementary file 2). They will be screened by study team members according to the eligibility criteria. Appointments will be scheduled for eligible participants to visit the participating hospitals or polyclinics for recruitment.

\section{Eligibility Criteria}

Participants must be Singapore Citizens or Permanent Residents, female, aged 35-59 years old. Women who have histologically confirmed diagnosis of any cancer, cognitive impairment which prevent the participant from giving voluntary consent, or are pregnant during recruitment will be excluded.

\section{First visit}

After providing informed consent, participants will be asked to complete a demographic and lifestyle questionnaire and provide a buccal swab sample. A brief education session on 
breast cancer knowledge and the importance of regular and timely breast selfexamination/screening will be self-administered by participants. Depending on their age, the participant will be advised to attend mammography (aged 40 years and above) breast screening. The session will end with a recruitment experience survey.

\section{First visit questionnaire}

Participants will fill in a structured questionnaire detailing various factors associated with the development of breast cancer and related conditions at baseline and over time. These include non-genetic risk factors (demographic, lifestyle, reproductive), past treatments and other environmental factors.

\section{Buccal swab, DNA extraction and genotyping}

Buccal swab (DNA Genotek, ORAcollect-DNA kit) samples will be de-identified and sent in batches (weekly) for deoxyribonucleic acid (DNA) extraction (QIAamp DNA Blood Midi Kit, Part No. 51185). Genotyping will be done (Illumina Global Screening Array [GSA-MD v3.0]) as per manufacturers' instructions.

DNA extracted from the bio-specimens will be stored in the freezer at -20 degrees Celsius for the duration of our research study. For participants who have agreed to the usage of their bio-specimens for future studies, DNA will be stored after study completion. 


\section{Breast cancer education session}

A brief online education session will first assess the screening habits of the participants and their views about breast cancer. Various statements regarding breast cancer will be presented for participants to indicate their agreement. The correct answer and an accompanying explanation are given after every response submitted. The aim is to impart correct information about breast cancer and the importance of regular and timely breast self-examination/screening.

\section{Mammography screening}

Participants may choose to attend screening within the next few months. The study coordinator will assist with setting up appointments for mammography screening with the participating institutions if required. If the participant (aged 40 and above) chooses to attend mammography screen, the study coordinator will seek consent to extract the mammogram image from the service provider (National Healthcare Group Diagnostics (NHGD)). Participants who had a recent mammogram (within one year prior to recruitment) done with NHGD can choose to provide consent for the study to extract the mammogram image.

\section{Experience Survey}

A short survey will be conducted to obtain feedback from the participants on their experience (including any discomfort) with the buccal swab and their initial views about risk-stratified breast cancer screening. 


\section{Risk stratification process and personal breast cancer risk report}

Participants will be classified as above average, average or below average risk, based on (1) the Gail model; (2) information from the most recent mammography screening (mammography density and positive recall status); (3) BOADICEA; and (4) the PRS. Participants will first be considered average risk and reclassified as above average or below average based on the criteria in Table 2 . A risk report will be produced and presented to the participant during the first follow-up session. All participants are recommended to follow current national guidelines (Table 3). In the BREATHE programme, women identified to be above average in breast cancer risk are referred to breast specialists at designated study sites, in addition to prevailing guidelines.

Table 2. Breast cancer risk reclassification criteria.

Individuals who met any one of the following criteria will be considered above average risk:

- Predicted to be carriers of BRCA1 or BRCA2 by BOADICEA

- Extremely dense breast, which is ascertained according to the breast composition categories of the Breast Imaging-Reporting and Data System (5th edition)

- Positive recall status

- Gail model five-year absolute risk above $1.3 \%{ }^{\wedge}$

- Polygenic Risk Score (PRS) five-year absolute risk above 3\%*

Individuals who met all of the following criteria will be considered below average risk:

- Age $<50$ years

- Gail model five-year absolute risk below $1.3 \%^{\wedge}$ 
- $\quad$ PRS five-year absolute risk below $1.3 \%^{\wedge}$

* The risk of an average $B R C A$ carrier (42). ${ }^{\wedge}$ The threshold of $1.3 \%$ is equivalent to the fiveyear absolute risk of developing breast cancer for an average Caucasian woman aged 50 years (43).

Table 3. National guidelines for breast cancer screening in Singapore.

\section{Age groups, years National guidelines}

35 to $39 \quad$ No recommendation

40 to $49 \quad$ Women are to attend yearly mammography screening, if

50 to $59 \quad$ Women are to attend mammography screening once every two years.

\section{Gail model (non-genetic risk factors)}

The Gail Model requires the following breast cancer risk factors from the questionnaire from the first visit: age, age at menarche, age at first live birth, number of previous benign breast biopsies, presence of atypical hyperplasia on biopsy, family history of breast cancer (mother, sisters or daughters), and ethnicity $(44,45)$. Weights (logistic regression coefficients derived from the Gail model) and attributable risks of Asian-Americans will be used in the calculation of five-year absolute risk based on the Gail model ("Asian.AABCS", BCRA package in R) (45). 


\section{Information from most recent mammography screening}

Mammographic density will be ascertained according to the breast composition categories of the Breast Imaging-Reporting and Data System (5th edition): almost entirely fatty, scattered areas of fibroglandular density, heterogeneously dense or extremely dense. A participant is considered recalled (i.e positive recall status) when she is asked to return for additional confirmatory examination or additional mammography views due to abnormal findings from initial screening.

Breast and Ovarian Analysis of Disease Incidence and Carrier Estimation Algorithm (BOADICEA) predictions for breast cancer predisposition genes Carrier probabilities for breast cancer predisposition genes such as BRCA1 and BRCA2 will be predicted using the Breast and Ovarian Analysis of Disease Incidence and Carrier Estimation Algorithm (BOADICEA) (40). Briefly, as described by Antoniou et al (40), the probability that an individual carries a mutation in BRCA1/BRCA2 or other breast cancer genes based on family history can be computed using Bayes theorem.

\section{Breast cancer polygenic risk score}

PRS is estimated as the weighted sum of effect alleles in 313 SNPs found to be associated with breast cancer; using PLINK (version 3) with the "scoresum" option (46).

$$
P R S=\beta_{1} x_{1}+\beta_{2} x_{2}+\cdots+\beta_{k} x_{k}+\cdots+\beta_{313} x_{313}
$$


where $x_{k}$ is the dosage of risk allele $(0-2)$ for SNP k, $\beta_{k}$ is the corresponding weight. The weights of the 313 SNPs for overall breast cancer risk were obtained from are of the overall breast cancer risk published by Mavaddat et al (47).

\section{First follow-up session}

The first follow-up session occurs within three months of the recruitment date. This involves an in-person review of the risk reports and ends with a survey on their understanding of the risk report. Participants will be reimbursed $\$ \$ 10$ for their time, inconvenience and transportation costs at the end of the first follow-up session.

\section{Second follow-up session}

This is the final in-person follow-up conducted for all participants and occurs approximately two years from date of recruitment. The study coordinator will administer a questionnaire on non-genetic risk factors to capture any changes in participant characteristics since the first visit. The session ends with a satisfaction survey to understand the acceptability of our proposed risk stratification screening programme.

Participants will be reimbursed $\$ \$ 10$ for their time, inconvenience and transportation costs at the end of the final study visit.

\section{Passive follow-up}

Mammogram images will be extracted if participants have undergone breast screening up to 31 March 2025. In addition, clinical information (e.g. radiology reports, medical conditions, medications and medical reports) related to this study will be retrieved from 
hospital/polyclinic medical records in accordance to the institutional guidelines, up to 31

December 2030. Clinical information may also be obtained through linkage to nation-wide health-related databases (Singapore Cancer Registry and the Registry of Births and Deaths), and may be done up to 31 December 2030.

\section{Planned Statistical Analysis}

To gauge the acceptability of risk stratification (Primary Aim 1) and the current level of breast cancer awareness (Secondary Aim 1), descriptive statistics will be performed. Chisquare test for categorical variables and Kruskal-Wallis test for continuous variables will be used for testing differences among risk groups. Post-hoc analysis may be applied for pairwise comparisons.

Logistic regression will be used to study the association between risk perceptions (i.e. risk categories and perceived risk) and follow-up events, which includes actual attendance of breast cancer screening and recall rates (Primary Aim 2 and Secondary Aim 2). Other modelling techniques will be employed dependent on event rates. Adjusted analysis may be done if variability in demographic variables are significant (e.g. conditional logistic models).

To understand potential short-term changes in breast cancer risk factors, paired analysis (e.g. paired-t-test, rank-sum test) between information from the first visit and follow-up will be performed (Secondary Aim 3). 
Taking the healthcare system perspective, a cost-utility analysis will be conducted to compare BREATHE's recommendation with the prevailing breast cancer screening guidelines using a Markov model (Aim 3). Additional costs associated with breast cancer risk profiling, and changes in healthcare expenditure and health outcomes for different risk groups will be examined. The incremental cost-effectiveness ratio (incremental cost/incremental quality-adjusted life years) will be calculated to understand the costeffectiveness of BREATH recommendations.

\section{Discussion}

Many previous works have evaluated the validity and discriminatory power of breast cancer risk calculators, alone or in combination $(27,28,48)$. In spite of the advances in breast cancer risk prediction, screening recommendations in practice have remained largely unchanged for the past few decades (23). Several large-scale studies conducted in populations of European ancestry, such as KARMA - KARolinska MAmmography Project for Risk Prediction of Breast Cancer (49), PROCAS - Predicting the Risk of Cancer at Screening (50), WISD0M - Women Informed to Screen Depending On Measures of risk (42), are already underway to evaluate the feasibility of implementing risk stratification in breast screening programmes. However, prediction tools should be validated and calibrated to the target population (51). To our knowledge, BREATHE is the first initiative to incorporate risk stratification approaches to enhance the efficacy of existing breast screening protocols in Asia. 
Our study leverages on the existing national breast cancer screening programme (BreastScreen Singapore, BSS) (21). Hence mammography service is consistent across all participants. The setup is scalable to include additional hospitals and polyclinics in the future. Singapore is geographically small and convenient for participants to visit breast clinics for recommendations to manage their breast cancer risk. While potential participants can visit multiple hospitals or polyclinics throughout our recruitment period, each individual's unique National Registration Identity Card number allows us to track them for follow-up. Loss to passive follow-up due to emigration is expected to be minimal for the duration of the study. The BREATHE risk classification is adapted from the established WISDOM Personalized Breast Cancer Screening Trial (42). WISDOM uses a fiveyear absolute risk threshold of $6 \%$ (risk of an average BRCA carrier) for stratification (42). However, it is known that the incidence of breast cancer among Asian women is lower (38, 42). Hence, the BREATHE study uses five-year absolute risk above $3 \%$ as a threshold (equivalent to women aged 50 years at the top risk percentile based on PRS in Singapore, data not shown).

BREATHE has some limitations worth noting. Selection bias may arise due to systematic differences between baseline characteristics of responders and non-responders to BREATHE's advertisements. BREATHE participants may be more health conscious or are already attending breast screening. Such a bias may affect sample representativeness and generalizability of findings. However, the BREATHE study collects information on the study participants (e.g. profession, socio-economic status, highest education attained) and how they found out about the study. This information will allow us to assess the implementation 
of a risk-based screening approach in this population first, before rolling out the initiative on a larger scale. The BREATHE risk report is based on information available from each participant. For example, if the participant does not participate in or is ineligible for mammography screening, information from first screen will not be in the risk report (participant is assumed to be of average risk). When information is incomplete, breast cancer risk will be underestimated. Barriers to active follow-up two years later are expected. However, the study coordinators will be actively contacting the participants to remind them about the follow-up visit. In addition, the questionnaire is designed such that the participant does not need to be present in-person (conducted electronically or over a phone call).

The aims of BREATHE are aligned with efforts to use personalized health for tailored interventions. For breast cancer screening, multiple studies have supported a riskstratified approach over the current age-based paradigm due to potentially higher costeffectiveness and reduced over-diagnosis $(13,24,52,53)$. If BREATHE is successful, women will gain a realistic understanding of their personal risk of breast cancer as well as strategies to reduce their risk, and fewer women will suffer from the anxiety of false positive mammograms and unnecessary biopsies. This work puts Singapore on the world map as a pioneer in integrating state-of-the-art breast cancer risk prediction tools, in particular, breast cancer PRS, in breast cancer screening. This study has real potential to transform breast cancer screening in Singapore. 
BREATHE has assembled a multidisciplinary team to build on best practices and emerging data from other risk-based breast cancer screening studies elsewhere. Data-driven and patient-centric value-based care will benefit the healthcare system in many aspects. At the personal level: Women will gain a realistic understanding of their personal breast cancer risk and be empowered to make informed decisions together with their physicians on strategies to manage their risk. At the clinic: The comprehensive risk classification will aid physicians in the conversation on the need for further genetic testing as well as screening and risk reduction strategies. At the population-level: BREATHE generates real-world evidence on how to change the breast cancer screening paradigm to recognize the different needs of individuals. This includes assessment of the organizational readiness, effectiveness, efficiency, resources, costs and cost-effectiveness of implementing a riskbased breast cancer screening approach in Singapore. BREATHE puts Singapore on the world map as one of the pioneers in integrating state-of-the-art risk prediction tools in breast cancer screening, with a real potential to transform the health system to deliver better health and healthcare outcomes. 


\section{Supplementary files}

File name: Supplementary file 1

File format: PDF

Title of data: Advertisement for BREATHE

Description of data: Advertisements including poster and study brochures for BREATHE.

File name: Supplementary file 2

File format: PDF

Title of data: Online registration form for BREATHE

Description of data: Online registration form for potential participants who are interested in BREATHE study.

\section{Declarations}

\section{Ethics approval and consent to participate}

This study will be conducted in accordance with the ethical principles that have their origin in the Declaration of Helsinki and that are consistent with the Good Clinical Practice and the applicable regulatory requirements, and was approved by the National Healthcare Group Domain Specific Review Board (reference no: 2020/01327). Informed consent will be obtained from the participants.

\section{Consent for publication}

Not applicable.

\section{Availability of data and materials}


Not applicable.

\section{Competing interests}

The authors declare that they have no competing interests.

\section{Funding}

BREATHE is funded by the JurongHealth Fund. MH is supported by the JurongHealth Fund, the Breast Cancer Prevention Programme under Saw Swee Hock School of Public Health Programme of Research Seed Funding (SSHSPH-Res-Prog), Breast Cancer Screening Prevention Programme (BCSPP) under Yong Loo Lin School of Medicine, National Medical Research Council Clinician Scientist Award (Senior Investigator Category, NMRC/CSASI/0015/2017), the National University Cancer Institute Singapore Centre Grant Programme (CGAug16M005), and Asian Breast Cancer Research Fund. JLi is supported by the National Research Foundation Singapore (NRF-NRFF2017-02).

\section{Authors' contributions}

Conceptualization, H.L.W., J.Li, P.T.C.I. and M.H.; Methodology, J.Liu, P.J.H., S.A.G., Y.W., H.L.W., J.Li, P.T.C.I. and M.H.; Investigation, A.J.K., J.Li, P.T.C.I. and M.H.; Resources, H.B.O., C.H.C., S.C.K., Z.P.Z., D.L.S.O., S.T.Q., C.C.T., J.Li, P.T.C.I. and M.H; Writing-original draft preparation, J.Liu, P.J.H., T.H.L.T. and J.Li; Writing-review and editing, all authors;

Supervision, H.B.O., C.H.C., S.C.K., Z.P.Z., D.L.S.O., S.T.Q., C.C.T., J.Li, P.T.C.I. and M.H; Project admin-istration, J.Liu, Y.S.Y., Y.J.C. and N.K.M.R.; Funding acquisition, J.Li and M.H. All authors have read and agreed to the published version of the manuscript. 
medRxiv preprint doi: https://doi.org/10.1101/2021.10.12.21264928; this version posted October 18, 2021. The copyright holder for this preprint (which was not certified by peer review) is the author/funder, who has granted medRxiv a license to display the preprint in perpetuity.

It is made available under a CC-BY 4.0 International license.

\section{Acknowledgements}

We want to thank our dedicated research and administrative staff - Ganga Devi D/0

Chandrasegran, Hui Min Lau, Pooi Yee Wong, Hui Ling Tan, Kimiie Chia Wei Lin, Nabilah

Binte Supiee, Nurfilya Binte Hamdil, Amanda Ong Tse Woon, Jing Jing Hong, Siew Li Tan,

Evelyn Low Sok Peng, Marina Mohd, Noor Aisha Binte Mohamed Bahru Ali and Linus Chui

for their contributions in the planning and preparation of BREATHE. 
medRxiv preprint doi: https://doi.org/10.1101/2021.10.12.21264928; this version posted October 18, 2021. The copyright holder for this preprint (which was not certified by peer review) is the author/funder, who has granted medRxiv a license to display the preprint in perpetuity.

It is made available under a CC-BY 4.0 International license.

Figure 1. Summary of the recruitment and follow-up process.

\section{First visit}

Eligible and consented participant to:

1. Complete a demographic and lifestyle questionnaire (First visit questionnaire)

2. Provide a buccal swab

3. Complete a brief breast cancer education survey

4. Fill in an experience survey
Bio-samples processing and DNA genotyping

\section{Risk stratification process and personal breast cancer risk report}

1. Participants are stratified into risk groups (above average, average or below average; Table 2)

2. Individual risk reports are produced

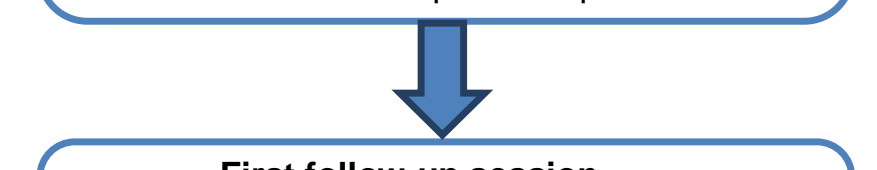

First follow-up session

1. In-person review of the risk reports

2. Complete a report feedback survey

3. Reimbursement of $\mathbf{S} \$ 10$

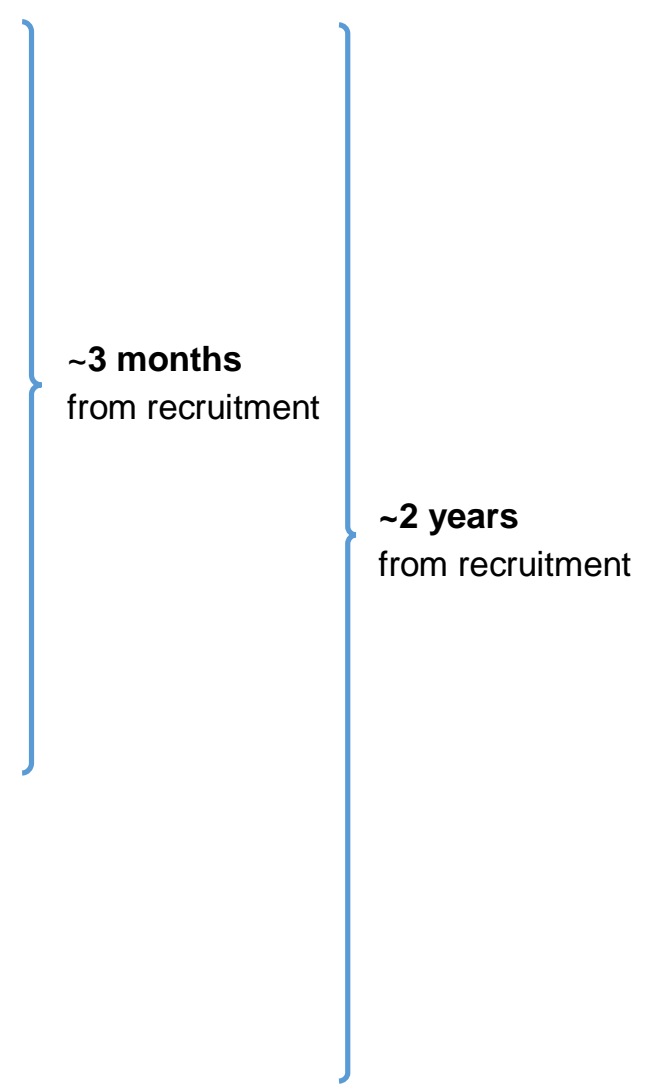

\section{Second follow-up session}

1. Complete a demographic and lifestyle questionnaire (follow-up questionnaire)

2. Participants fills in satisfaction survey

3. Reimbursement of $\mathbf{S} \$ 10$

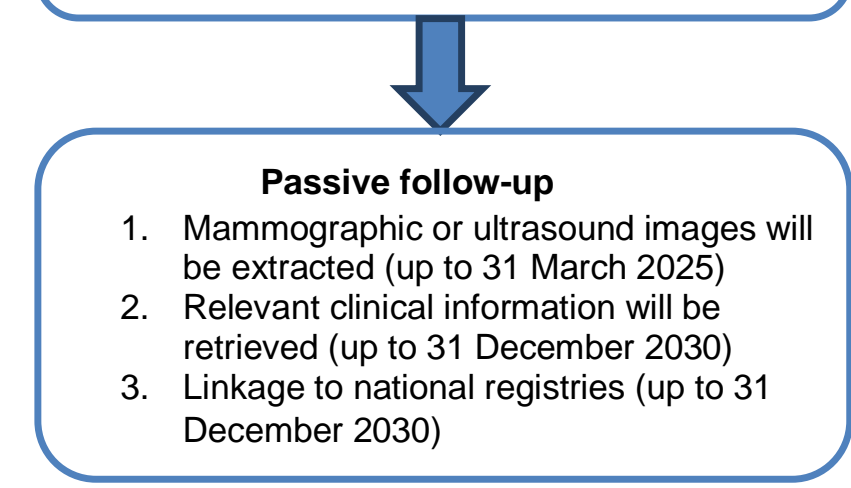


medRxiv preprint doi: https://doi.org/10.1101/2021.10.12.21264928; this version posted October 18, 2021. The copyright holder for this preprint (which was not certified by peer review) is the author/funder, who has granted medRxiv a license to display the preprint in perpetuity.

It is made available under a CC-BY 4.0 International license .

\section{References}

1. Independent UKPoBCS. The benefits and harms of breast cancer screening: an independent review. Lancet. 2012;380(9855):1778-86.

2. Fischer C, Kuchenbacker K, Engel C, Zachariae S, Rhiem K, Meindl A, et al. Evaluating the performance of the breast cancer genetic risk models BOADICEA, IBIS, BRCAPRO and Claus for predicting BRCA1/2 mutation carrier probabilities: a study based on 7352 families from the German Hereditary Breast and Ovarian Cancer Consortium. J Med Genet. 2013;50(6):3607.

3. Yanes T, Young MA, Meiser B, James PA. Clinical applications of polygenic breast cancer risk: a critical review and perspectives of an emerging field. Breast Cancer Res. 2020;22(1):21.

4. Gagnon J, Levesque E, Clinical Advisory Committee on Breast Cancer S, Prevention, Borduas $\mathrm{F}$, Chiquette $\mathrm{J}$, et al. Recommendations on breast cancer screening and prevention in the context of implementing risk stratification: impending changes to current policies. Curr Oncol. 2016;23(6):e615-e25.

5. Tehranifar P, Wei Y, Terry MB. Less Is More-Ways to Move Forward for Improved Breast Cancer Risk Stratification. Cancer Epidemiol Biomarkers Prev. 2021;30(4):587-9.

6. Gotzsche PC, Jorgensen KJ. Screening for breast cancer with mammography. Cochrane Database Syst Rev. 2013(6):CD001877.

7. Miller AB, Wall C, Baines CJ, Sun P, To T, Narod SA. Twenty five year follow-up for breast cancer incidence and mortality of the Canadian National Breast Screening Study: randomised screening trial. BMJ. 2014;348:g366.

8. Bleyer A, Welch HG. Effect of three decades of screening mammography on breastcancer incidence. N Engl J Med. 2012;367(21):1998-2005.

9. Canelo-Aybar C, Ferreira DS, Ballesteros M, Posso M, Montero N, Sola I, et al. Benefits and harms of breast cancer mammography screening for women at average risk of breast cancer: A systematic review for the European Commission Initiative on Breast Cancer. J Med Screen. 2021:969141321993866.

10. McWilliams L, Woof VG, Donnelly LS, Howell A, Evans DG, French DP. Risk stratified breast cancer screening: UK healthcare policy decision-making stakeholders' views on a lowrisk breast screening pathway. BMC Cancer. 2020;20(1):680.

11. Hall $\mathrm{P}$, Easton D. Breast cancer screening: time to target women at risk. $\mathrm{Br} \mathrm{J}$ Cancer. 2013;108(11):2202-4.

12. Raat HPJ, Lobbes MBI, Veldhuis WB. [Are The Netherlands ready for personalized breast cancer screening? Abbreviated breast MRI and contrast-enhanced mammography for screening in women with dense breasts]. Ned Tijdschr Geneeskd. 2021;165.

13. Narod SA. Personalised medicine and population health: breast and ovarian cancer. Hum Genet. 2018;137(10):769-78.

14. Kim G, Bahl M. Assessing Risk of Breast Cancer: A Review of Risk Prediction Models. J Breast Imaging. 2021;3(2):144-55.

15. Delaloge S, Bachelot T, Bidard FC, Espie M, Brain E, Bonnefoi H, et al. [Breast cancer screening: On our way to the future]. Bull Cancer. 2016;103(9):753-63.

16. Teo CT, Yeo YW, Lee SC. Screening mammography behavior and barriers in Singaporean Asian women. Am J Health Behav. 2013;37(5):667-82.

17. Malhotra C, Bilger M, Liu J, Finkelstein E. Barriers to Breast and Cervical Cancer Screening in Singapore: a Mixed Methods Analysis. Asian Pac J Cancer Prev. 2016;17(8):388795.

18. Wong HZ, Lim WY, Ma SS, Chua LA, Heng DM. Health Screening Behaviour among Singaporeans. Ann Acad Med Singap. 2015;44(9):326-34. 
medRxiv preprint doi: https://doi.org/10.1101/2021.10.12.21264928; this version posted October 18, 2021. The copyright holder for this preprint (which was not certified by peer review) is the author/funder, who has granted medRxiv a license to display the preprint in perpetuity. It is made available under a CC-BY 4.0 International license .

19. Wong XY, Chong KJ, van Til JA, Wee HL. A qualitative study on Singaporean women's views towards breast cancer screening and Single Nucleotide Polymorphisms (SNPs) gene testing to guide personalised screening strategies. BMC Cancer. 2017;17(1):776.

20. Lim SK, Teo XL, Ng JL, Li FX, Tan SM. A Survey on Singaporean Women's Knowledge, Perception and Practices of Mammogram Screening. Ann Acad Med Singap. 2015;44(9):31725.

21. Loy EY, Molinar D, Chow KY, Fock C. National Breast Cancer Screening Programme, Singapore: evaluation of participation and performance indicators. J Med Screen. 2015;22(4):194-200.

22. Ho PJ, Lau HSH, Ho WK, Wong FY, Yang Q, Tan KW, et al. Incidence of breast cancer attributable to breast density, modifiable and non-modifiable breast cancer risk factors in Singapore. Sci Rep. 2020;10(1):503.

23. Leong SP, Shen ZZ, Liu TJ, Agarwal G, Tajima T, Paik NS, et al. Is breast cancer the same disease in Asian and Western countries? World J Surg. 2010;34(10):2308-24.

24. Vilaprinyo E, Forne C, Carles M, Sala M, Pla R, Castells X, et al. Cost-effectiveness and harm-benefit analyses of risk-based screening strategies for breast cancer. PLoS One. 2014;9(2):e86858.

25. Pons-Rodriguez A, Forne Izquierdo C, Vilaplana-Mayoral J, Cruz-Esteve I, SanchezLopez I, Rene-Rene M, et al. Feasibility and acceptability of personalised breast cancer screening (DECIDO study): protocol of a single-arm proof-of-concept trial. BMJ Open. 2020;10(12):e044597.

26. Albright FS, Kohlmann W, Neumayer L, Buys SS, Matsen CB, Kaphingst KA, et al. Population-based relative risks for specific family history constellations of breast cancer. Cancer Causes Control. 2019;30(6):581-90.

27. Wang X, Huang Y, Li L, Dai H, Song F, Chen K. Assessment of performance of the Gail model for predicting breast cancer risk: a systematic review and meta-analysis with trial sequential analysis. Breast Cancer Res. 2018;20(1):18.

28. Nazari SS, Mukherjee P. An overview of mammographic density and its association with breast cancer. Breast Cancer. 2018;25(3):259-67.

29. Antoniou AC, Hardy R, Walker L, Evans DG, Shenton A, Eeles R, et al. Predicting the likelihood of carrying a BRCA1 or BRCA2 mutation: validation of BOADICEA, BRCAPRO, IBIS, Myriad and the Manchester scoring system using data from UK genetics clinics. J Med Genet. 2008;45(7):425-31.

30. Wong ESY, Shekar S, Met-Domestici M, Chan C, Sze M, Yap YS, et al. Inherited breast cancer predisposition in Asians: multigene panel testing outcomes from Singapore. NPJ Genom Med. 2016;1:15003.

31. Lim GH, Borje E, Allen JC, Jr. Evaluating the performance of National Comprehensive Cancer Network (NCCN) breast and ovarian genetic/familial high risk assessment referral criteria for breast cancer women in an Asian surgical breast clinic. Gland Surg. 2017;6(1):35-42.

32. Couch FJ, Nathanson KL, Offit K. Two decades after BRCA: setting paradigms in personalized cancer care and prevention. Science. 2014;343(6178):1466-70.

33. Pederson HJ, Noss R. Updates in hereditary breast cancer genetic testing and practical high risk breast management in gene carriers. Semin Oncol. 2020;47(4):182-6.

34. Lee JY, Kim J, Kim SW, Park SK, Ahn SH, Lee MH, et al. BRCA1/2-negative, high-risk breast cancers (BRCAX) for Asian women: genetic susceptibility loci and their potential impacts. Sci Rep. 2018;8(1):15263.

35. Mahdi KM, Nassiri MR, Nasiri K. Hereditary genes and SNPs associated with breast cancer. Asian Pac J Cancer Prev. 2013;14(6):3403-9.

36. Mavaddat N, Pharoah PD, Michailidou K, Tyrer J, Brook MN, Bolla MK, et al. Prediction of breast cancer risk based on profiling with common genetic variants. J Natl Cancer Inst. 2015;107(5). 
medRxiv preprint doi: https://doi.org/10.1101/2021.10.12.21264928; this version posted October 18, 2021. The copyright holder for this preprint (which was not certified by peer review) is the author/funder, who has granted medRxiv a license to display the preprint in perpetuity. It is made available under a CC-BY 4.0 International license .

37. Chan CHT, Munusamy P, Loke SY, Koh GL, Yang AZY, Law HY, et al. Evaluation of three polygenic risk score models for the prediction of breast cancer risk in Singapore Chinese. Oncotarget. 2018;9(16):12796-804.

38. Ho WK, Tan MM, Mavaddat N, Tai MC, Mariapun S, Li J, et al. European polygenic risk score for prediction of breast cancer shows similar performance in Asian women. Nat Commun. 2020;11(1):3833.

39. Weigel S, Heindel W, Dietz C, Meyer-Johann U, Graewingholt A, Hense HW. Stratification of Breast Cancer Risk in Terms of the Influence of Age and Mammographic density. Rofo. 2020;192(7):678-85.

40. Antoniou AC, Pharoah PP, Smith P, Easton DF. The BOADICEA model of genetic susceptibility to breast and ovarian cancer. Br J Cancer. 2004;91(8):1580-90.

41. Chootipongchaivat S, Wong XY, Ten Haaf K, Hartman M, Tan KB, van Ravesteyn NT, et al. Cost-effectiveness Analysis of Breast Cancer Screening Using Mammography in Singapore: A Modeling Study. Cancer Epidemiol Biomarkers Prev. 2021;30(4):653-60.

42. Esserman LJ, Study W, Athena I. The WISDOM Study: breaking the deadlock in the breast cancer screening debate. NPJ Breast Cancer. 2017;3:34.

43. Shieh Y, Eklund M, Madlensky L, Sawyer SD, Thompson CK, Stover Fiscalini A, et al. Breast Cancer Screening in the Precision Medicine Era: Risk-Based Screening in a PopulationBased Trial. J Natl Cancer Inst. 2017;109(5).

44. Costantino JP, Gail MH, Pee D, Anderson S, Redmond CK, Benichou J, et al. Validation studies for models projecting the risk of invasive and total breast cancer incidence. J Natl Cancer Inst. 1999;91(18):1541-8.

45. Gail MH, Brinton LA, Byar DP, Corle DK, Green SB, Schairer C, et al. Projecting individualized probabilities of developing breast cancer for white females who are being examined annually. J Natl Cancer Inst. 1989;81(24):1879-86.

46. Purcell S, Neale B, Todd-Brown K, Thomas L, Ferreira MA, Bender D, et al. PLINK: a tool set for whole-genome association and population-based linkage analyses. Am J Hum Genet. 2007;81(3):559-75.

47. Mavaddat N, Michailidou K, Dennis J, Lush M, Fachal L, Lee A, et al. Polygenic Risk Scores for Prediction of Breast Cancer and Breast Cancer Subtypes. Am J Hum Genet. 2019;104(1):21-34.

48. Rudolph A, Song M, Brook MN, Milne RL, Mavaddat N, Michailidou K, et al. Joint associations of a polygenic risk score and environmental risk factors for breast cancer in the Breast Cancer Association Consortium. Int J Epidemiol. 2018;47(2):526-36.

49. Chikarmane SA, Cochon LR, Khorasani R, Sahu S, Giess CS. Screening Mammography Performance Metrics of 2D Digital Mammography Versus Digital Breast Tomosynthesis in Women With a Personal History of Breast Cancer. AJR Am J Roentgenol. 2021:1-8.

50. Evans DGR, Harkness EF, Brentnall AR, van Veen EM, Astley SM, Byers $H$, et al. Breast cancer pathology and stage are better predicted by risk stratification models that include mammographic density and common genetic variants. Breast Cancer Res Treat. 2019;176(1):141-8.

51. Gail MH. Choosing Breast Cancer Risk Models: Importance of Independent Validation. J Natl Cancer Inst. 2020;112(5):433-5.

52. Wong XY, Groothuis-Oudshoorn CG, Tan CS, van Til JA, Hartman M, Chong KJ, et al. Women's preferences, willingness-to-pay, and predicted uptake for single-nucleotide polymorphism gene testing to guide personalized breast cancer screening strategies: a discrete choice experiment. Patient Prefer Adherence. 2018;12:1837-52.

53. Pashayan N, Morris S, Gilbert FJ, Pharoah PDP. Cost-effectiveness and Benefit-toHarm Ratio of Risk-Stratified Screening for Breast Cancer: A Life-Table Model. JAMA Oncol. 2018;4(11):1504-10. 